\title{
POWER QUALITY DIAGNOSIS IN DISTRIBUTION NETWORK USING WAVELET TRANSFORM
}

\author{
${ }^{1}$ H.H. Goh, ${ }^{1}$ H.L. Ting, ${ }^{1}$ Q.S. Chua, ${ }^{1}$ S.W. Lee, ${ }^{2}$ K.C. Goh and ${ }^{3}$ K.T.K. Teo \\ ${ }^{1}$ Department of Electrical Power Engineering, Faculty of Electrical and Electronic Engineering, \\ ${ }^{2}$ Department of Construction Management, Faculty of Technology Management and Business, \\ Universiti Tun Hussein Onn Malaysia, 86400 Parit Raja, BatuPahat, Johor, Malaysia \\ ${ }^{3}$ Modelling, Simulation and Computing Laboratory, Level 3, Block C, \\ School of Engineering and Information Technology, Jalan UMS, \\ Universiti Malaysia Sabah, 88400 Kota Kinabalu, Sabah, Malaysia
}

Received 2013-11-27; Revised 2013-11-27; Accepted 2013-12-26

\begin{abstract}
Power quality is one of the most concerns to the electric power suppliers, equipment manufacturers and the users of various electrical and electronic equipments. This paper presents the use of a continuous wavelet transform to detect and analyse voltage sags and swells. Characteristics which include duration and magnitude of the investigated signals are measured. Unlike other approaches where the detection is performed directly in the time domain, while the detection by using wavelet transform analysis approach is carried out in the time-scale domain. The wavelet function Daubechies4 is used as the base function in detection and identification because of its frequency response and information time localization properties. The measured parameters and characteristics are being compared by implementing the SPSS software. The whole method is contrived and tested over a sample representing recorded disturbances. The results showed that Daubechie4 is best suited for detect and localize voltage sags and swells for $50 \mathrm{~Hz}$ system, while Daubechie10 is suited to determine smooth disturbances. The success percentage obtained for the entire tested disturbance's signal was more than $90 \%$.
\end{abstract}

Keywords: Continuous Wavelet Transform, Daubechies4, IBM SPSS Statistics, Time-Scale Domain, Voltage Sags, Voltage Swells

\section{INTRODUCTION}

Power quality is a set of boundaries that allow equipment functions in their intended manner without any significant loss of performance and life expectancy. Poor power quality will cause power line disturbances. Recent years, power quality has become the most essential issue to consider for any electronic devices or machine (Kopparapu and Chandrasekaran, 1998; Dehghani, 2009). Due to the large utilization of power electronic in the power system, there is a need to diagnosis the power quality in the distribution networks in order to reduce the risk of equipment damage and cost.

\section{Corresponding Auther:}

H.H. Goh, Department of Electrical Power Engineering, Faculty of Electrical and Electro
Universiti Tun Hussein Onn Malaysia, 86400 Parit Raja, BatuPahat, Johor, Malaysia 
used for detecting and identifying disturbances with wavelet window, Daubechies4. Previous researches (Santoso et al., 1994; Bingham, 1998; Kopparapu and Chandrasekaran, 1998; Kim et al., 1999; Poisson et al., 2000; Dugan et al., 2012; Basu and Basu, 2004; Kanitpanyacharoean and Premrudeepreechacharn, 2004; Kasula, 2007; Milind et al., 2008; Talaat et al., 2008), which study about performance of wavelet have proposed several methods to diagnosis the power quality problem.

In this research project, the entire tested signals are $22 \mathrm{kV}, 50 \mathrm{~Hz}$. The analysis starts with monitoring and collecting the disturbances' waveform and then the disturbances' waveform is being converted into numerical value by using the power quality recorder. After that, wavelet transform is applied to extract and analyze the data. Some parameters which include standard deviation, mean are recorded and compare with recorded parameter using SPSS.

The paper is organized into five sections. Section 2 provides background information of Power Quality Disturbances and Wavelet Transform. The methodology used for the evaluation in disturbances diagnosis is described in section 3. A case study involving a sample of disturbance is presented in section 4. The last section provides a major conclusion and indicates the direction to future work.

\subsection{Background Information \\ 1.1.1. Overview of Power Quality Disturbances}

In this research project, the short-duration variation disturbances are considered. Normally, the shortduration variations are caused by energization of load, loose connections in power wiring and transient fault conditions. The faults will indirectly cause voltage sags, voltage swells and interruptions.

Sags referred to any reduction in voltage below a userdefined low limit as shown in Fig. 1. The reduction of voltage is between $10 \%$ and $90 \%$ and lasting for 0.5 cycles to several seconds. For sag that less than half a cycle is regarded as transients. Voltage sag usually happens when a temporary disconnection of supply, the flow of heavy current associated from the start of large motor loads or the flow of fault current. The effect of voltage sag to equipment depends on both its magnitude and its duration.

Swells were similar to sags, except that the voltage exceeded a user-defined high limit and is illustrated in Fig. 2. Voltage swell is defined as an increase up to a level between $110 \%$ and $180 \%$ in rms voltage of the power frequency for periods ranging from a half cycle to a minute as shows. Normally, voltage swell occurs when the line faults and incorrect tap settings in tap changers in substations.

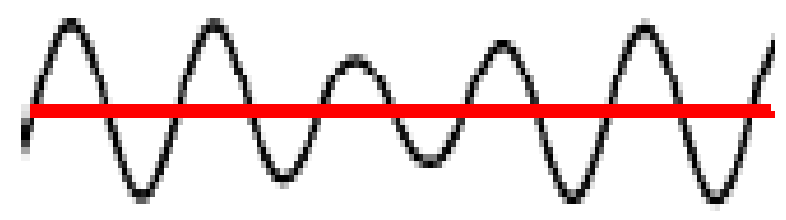

Fig. 1. Voltage sag

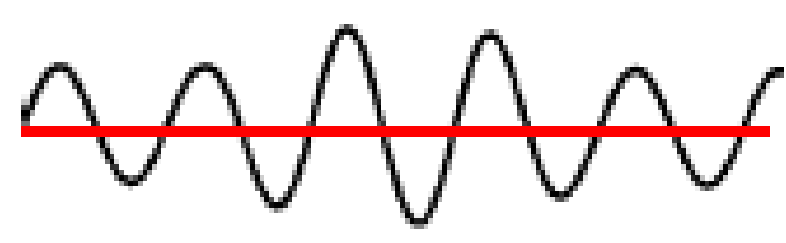

Fig. 2. Voltage swell

Table 1. Categories and characteristic of sag and swell phenomena

\begin{tabular}{cll}
\hline Categories & $\begin{array}{l}\text { Typical } \\
\text { duration }\end{array}$ & $\begin{array}{l}\text { Typical voltage } \\
\text { magnitude }\end{array}$ \\
\hline $\begin{array}{c}\text { 1.0 Short duration variation } \\
\text { 1.1 Instantaneous }\end{array}$ & & \\
1.1.1 Sag & $0.5-30$ cycles & $0.1-0.9 \mathrm{p} . \mathrm{u}$ \\
1.1.2 Swell & $0.5-30$ cycles & $1.1-1.8 \mathrm{p} . \mathrm{u}$ \\
1.2 Momentary & & \\
1.2.1 Sag & 30 cycles-3s & $0.1-0.9 \mathrm{p} . \mathrm{u}$ \\
1.2.2 Swell & 30 cycles-3s & $1.1-1.4 \mathrm{p} . \mathrm{u}$ \\
1.3 Temporary & $3 \mathrm{~s}-1 \mathrm{~min}$ & $0.1-0.9 \mathrm{p} . \mathrm{u}$ \\
1.3.1 Sag & $3 \mathrm{~s}-1 \mathrm{~min}$ & $1.1-1.2 \mathrm{p} . \mathrm{u}$ \\
\hline
\end{tabular}

In addition to the above definitions, the IEEE 1159 document further classifies the duration values into three categories: Instantaneous, momentary and temporary which have been provided in Table 1.

\subsection{Overview of Wavelet Transform}

Wavelet analysis is applied to the disturbances signal obtained. It provides a representation in both time and frequency of tested signal, which enhances the purpose of detecting transition events in power quality. The wavelet transform decomposes the disturbances signal into detailed and smooth versions. The wavelet analysis uses short windows at high frequencies and long windows at low frequencies. The frequency bands that represent each resolution level are summarized in Table 2. From Table 2, level 6-7 are more important levels that contain the main features of signal with normal frequency $50 \mathrm{~Hz}$. 
Table 2. Detail and approximation coefficients

\begin{tabular}{llll}
\hline $\begin{array}{l}\text { Approximation } \\
\text { coefficients }\end{array}$ & $\begin{array}{l}\text { Frequency } \\
\text { band }(\mathrm{Hz})\end{array}$ & $\begin{array}{l}\text { Detail } \\
\text { coefficients }\end{array}$ & $\begin{array}{l}\text { Frequency } \\
\text { band }(\mathrm{Hz})\end{array}$ \\
\hline A1 & $0-2500$ & D1 & $2500-5000$ \\
A2 & $0-1250$ & D2 & $1250-2500$ \\
A3 & $0-625$ & D3 & $625-1250$ \\
A4 & $0-31.5$ & D4 & $312.5-625$ \\
A5 & $0-156.25$ & D5 & $156.25-312.65$ \\
A6 & $0-78.125$ & D6 & $78.125-156.25$ \\
A7 & $0-39.062$ & D7 & $39.062-78.125$ \\
A8 & $0-19.531$ & D8 & $19.531-39.062$ \\
A9 & $0-9.765$ & D9 & $9.765-19.531$ \\
\hline
\end{tabular}

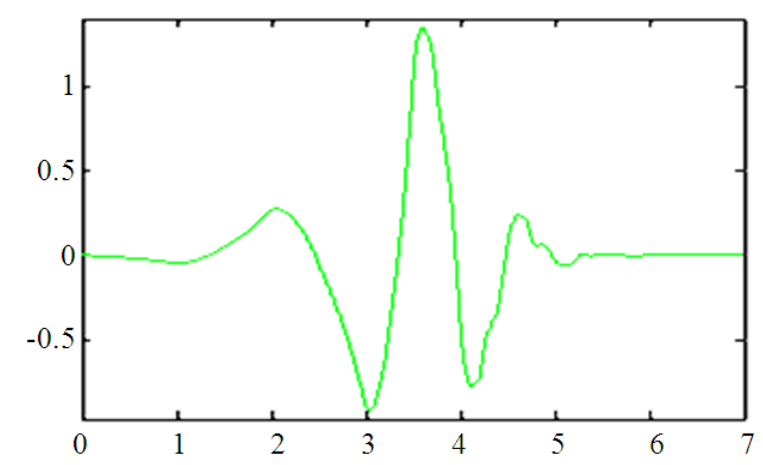

Fig. 3. Daubechies' wavelet with 4 filters coefficients.

The detection and localization of different types of power quality disturbances is greatly influenced by the choice of analyzing wavelets. Daubechies4 and Daubechie6 wavelets in the Matlab Wavelet Toolbox are better suited for short and fast transient disturbances, while Daubechies8 and Daubechies10 are particularly suited for slow and long transient disturbances. Therefore, Daubechies4 and Daubechies6 are more appropriate choices. In the project, Daubechies4 (Fig. 3) was adopted in capturing all disturbance's types.

\section{MATERIALS AND METHODS}

Methodology is an important section to be focused on because the overall progress on the project is previewed. The project is conducting in phase's basis as follows:

Phase 1: Literature studies

Phase 2: Database conversion using Reliable Power Meter

Phase 3: Data analysis using SPSS

Phase 4: Detection and localization using Wavelet transform method

Phase 5: Manipulated data being compared between both analysis tools
Generally, system frequency in Peninsular Malaysia is $50 \mathrm{~Hz}$. Therefore, the system frequency is around $50 \mathrm{~Hz}$ for all sites in the south distribution region in Malaysia. The power quality disturbances were recorded on the $22 \mathrm{kV}$ distribution network in Skudai, Johor, Malaysia. The significant disturbances were recorded over a few month periods.

The database obtained from the Southern Region, Phasor Measurement Unit (PMU) Skudai, Johor, Malaysia is being imported into the Reliable Power Meter software. The disturbances are being selected and identified and then converted into a text file where the disturbances' waveform is presented in numerical value for further analyse in Matlab toolbox and SPSS software. The most commonly occurring disturbances, i.e. voltage sags and voltage swells signal with nominal frequency $50 \mathrm{~Hz} ; 22 \mathrm{kV}$ are being analyzed.

The decomposition by wavelet transforms method using Matlab Toolbox results in an approximation and detail coefficient. The parameter such as standard deviation, number of cycle in voltage sag and swell durations are being studied and analyzed by using SPSS software. The process of the disturbances' detection, estimation and classification basically consists of the following blocks is shown in Fig. 4.

\section{RESULTS AND DISCUSSION}

\subsection{Results for Power Quality Disturbance}

The curve shown in Fig. 5 is the Computer Business Equipment Manufacturers Association (CBEMA) curve in Reliable Power Meter software where Y-axis of the curve represents the nominal voltage amplitude and $\mathrm{X}$ axis represent the time after the events occurred. Figure 6 shows one of the voltage sag events being selected from the dotted in CBEMA curve.

A set of pure signal and different disturbances (sags, swells) have been analysed with a subset of 34 voltage swells and 77 voltage sags. The parameters which include maximum and minimum value and standard deviation are studied using both Matlab and SPSS software. For this paper, the value of standard deviation, which is one of the parameters obtained from both methods, is being compared. The comparison is present in the form on the bar chart as provided in Fig. 7.

Other than the parameters mention earlier, the histogram is also one of the ways to distinguish the type of disturbances where it can provide a visual sense of the frequency distribution. The histogram of the pure signal is constructed in Fig. 8. For a disturbance's signal, the histogram shows a non-symmetrical distribution of data as shown in Fig. 9. 
H.H. Goh et al. / American Journal of Applied Sciences 11 (2): 291-300, 2014

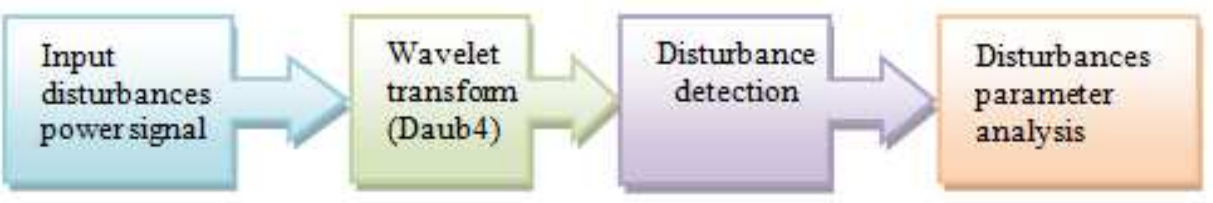

Fig. 4. Power disturbances detection and classification process

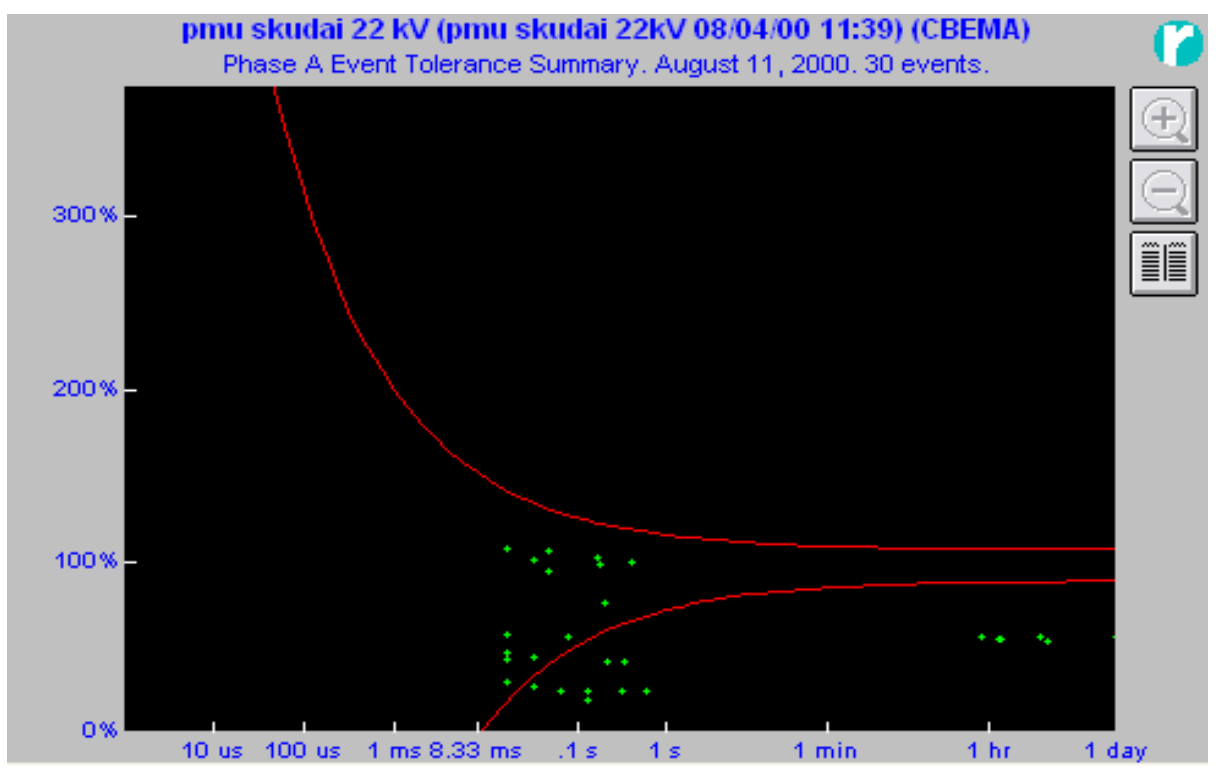

Fig. 5. The events and the summaries for Skudai Distribution network

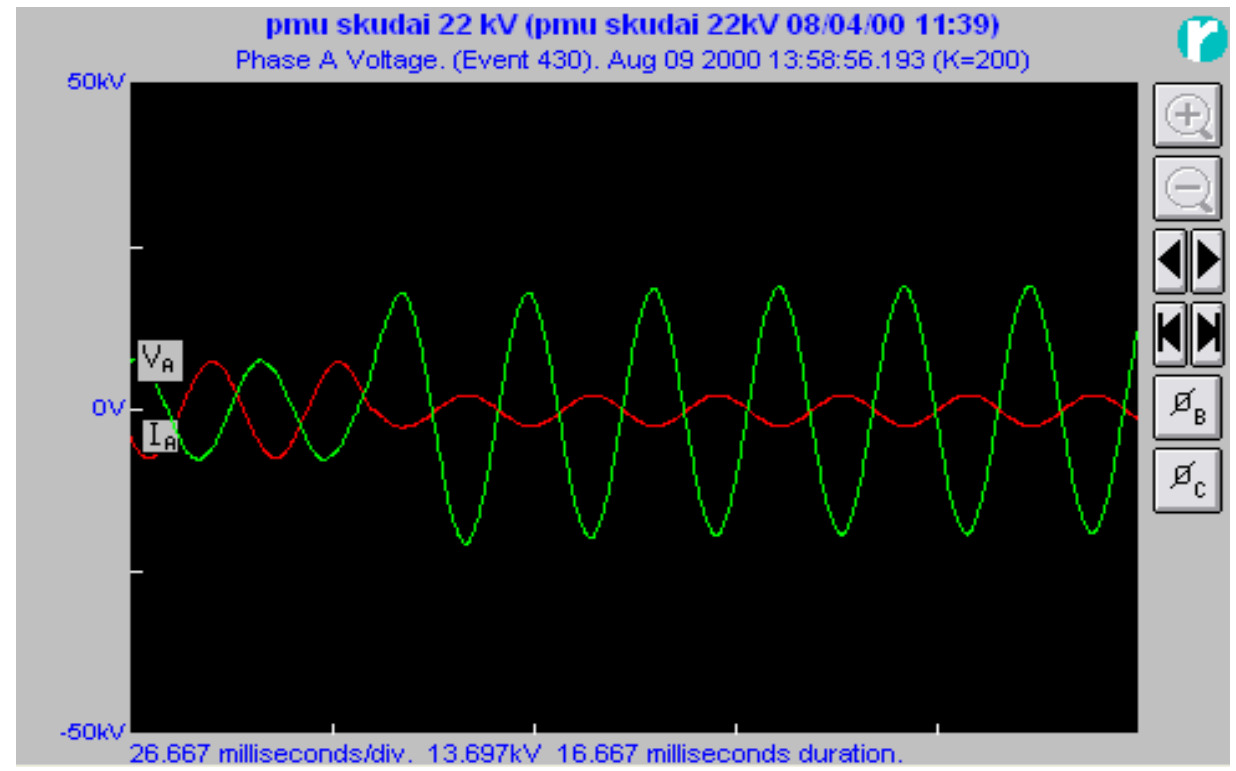

Fig. 6. The voltage sag event 


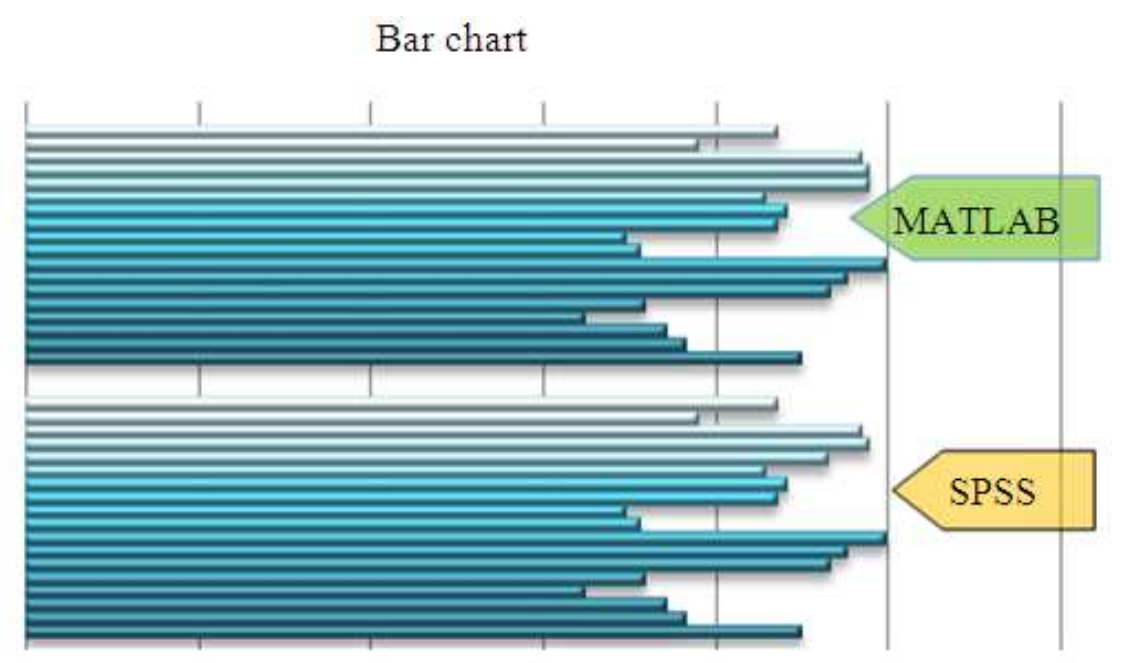

Fig. 7. Bar chart of number of cases against standard deviation

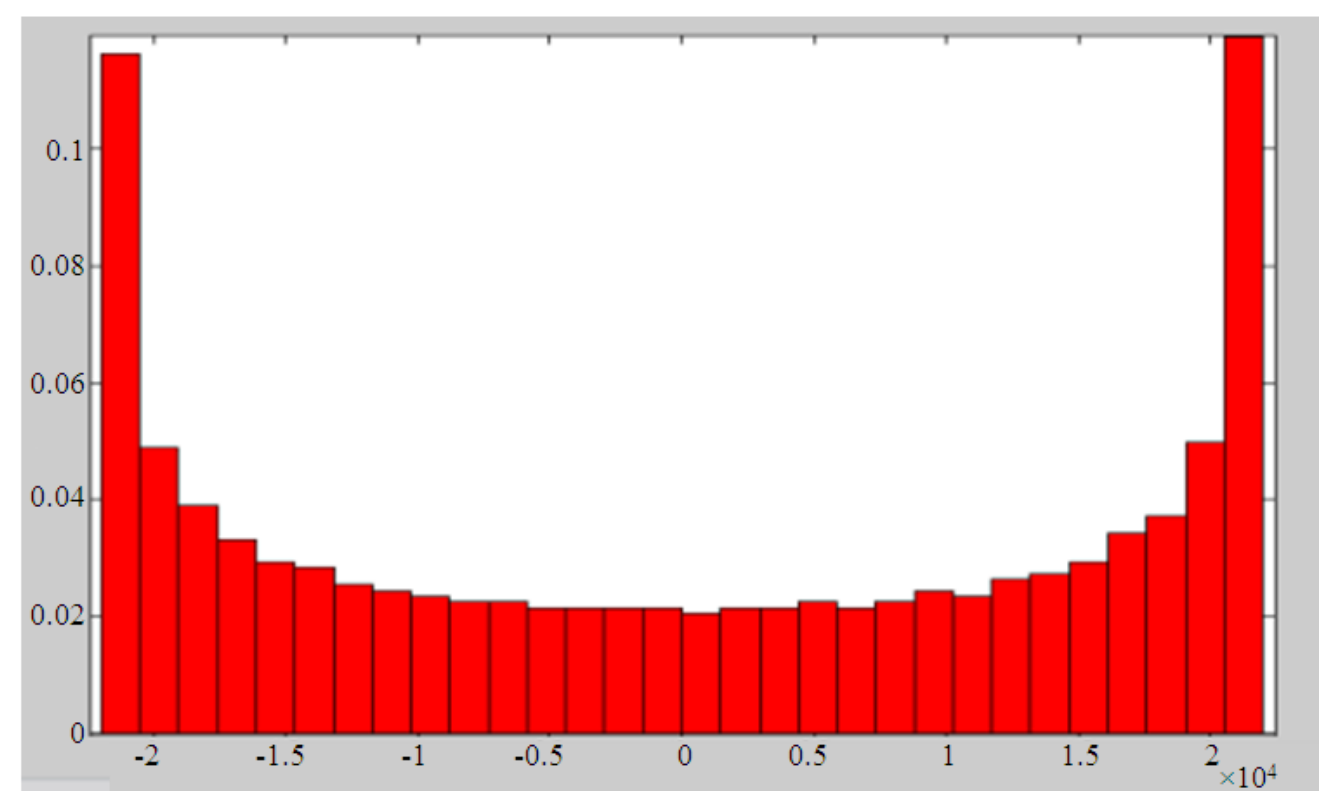

Fig. 8. Histogram of pure signal

In Fig. 10, by implementing the Matlab Toolbox, the detection of sag on a $50 \mathrm{~Hz}$ signal by using six detail levels with wavelet transform daubechies4 is illustrated.

It is important to note that for all practical purposes, Daub4 fails to detect this smooth disturbance. However, this disturbance is well detected with Daub10. Figure 11 shows an example of smooth sags.
The colour map indicator is illustrated in Fig. 12. The colour varies from the indigo to red indicate the amplitude of the signal varies from minimum to maximum. This colour map indicator act as a scale to verify the amplitude of the signal.

The wavelet transform analysis for sag disturbances in the superimpose mode by using Matlab toolbox is shown in Fig. 13. 


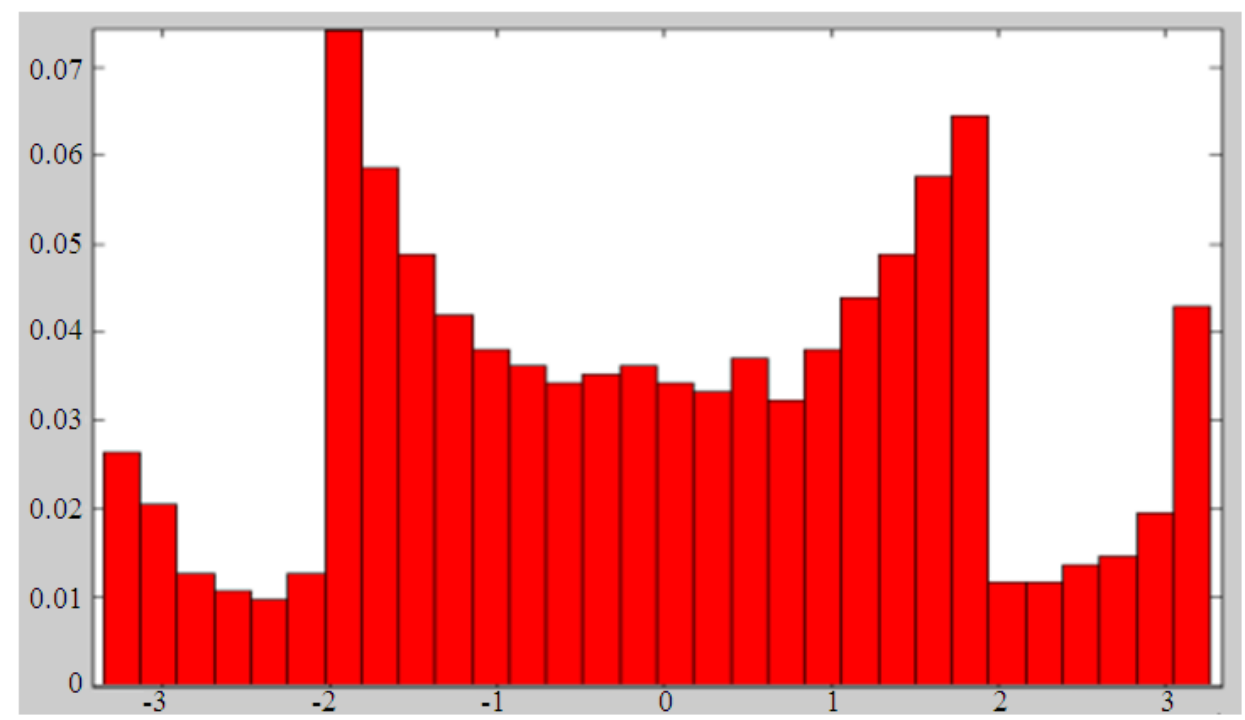

Fig. 9. Histogram of disturbance signal

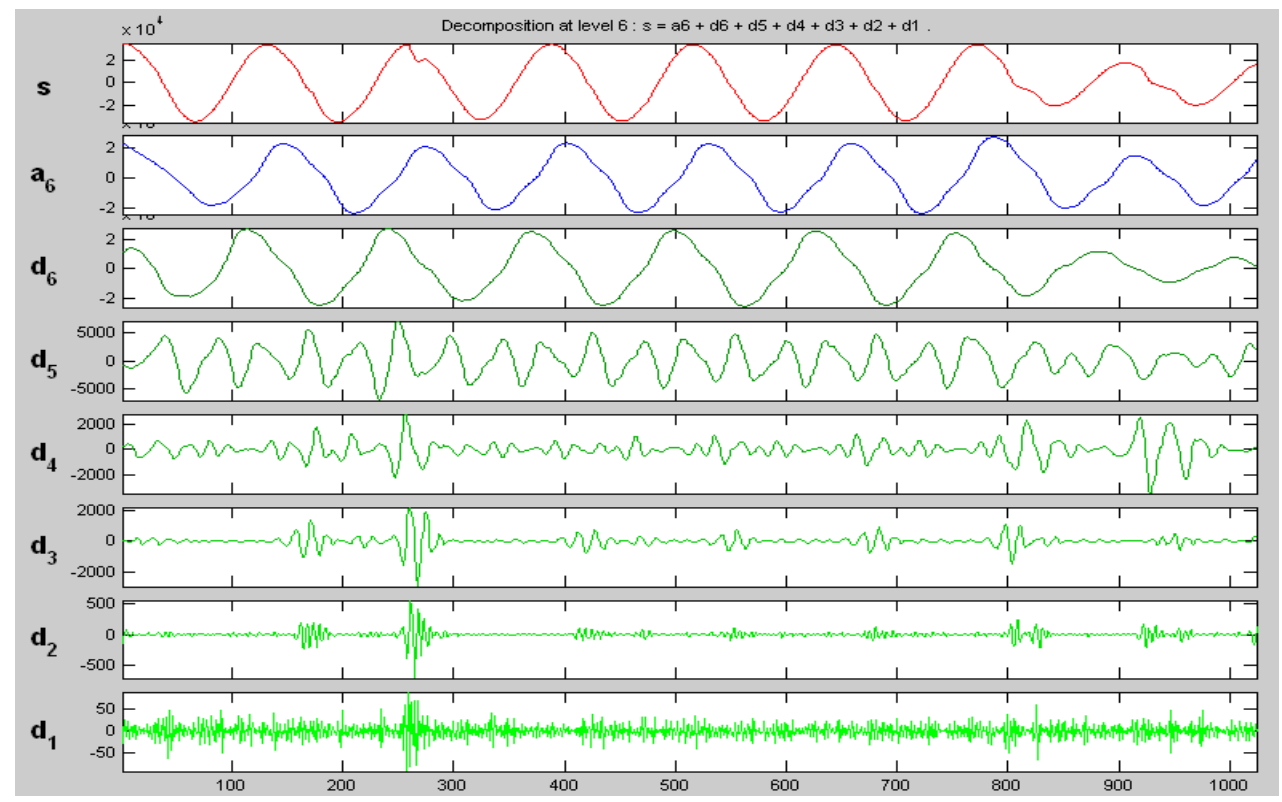

Fig. 10. Sag disturbances and six level of detail using Daubechies4

\subsection{Analysis for Power Quality Disturbance}

This section will discuss the strategies to detect and identify the power quality disturbances.

By referring to the Fig. 5, the green dotted to represent the power disturbances' events. Each green dotted point on the CBEMA curve has been selected to further analyze. The selected power disturbances' events are then being converted into text file and import into SPSS and Matlab. In this study, voltage sags are taken as an example of the case study.

The time and duration of the disturbances and the data of the power disturbances are recorded for each disturbances signal to achieve Fig. 6. The recorded duration for the voltage sag is 16.667 milliseconds. 


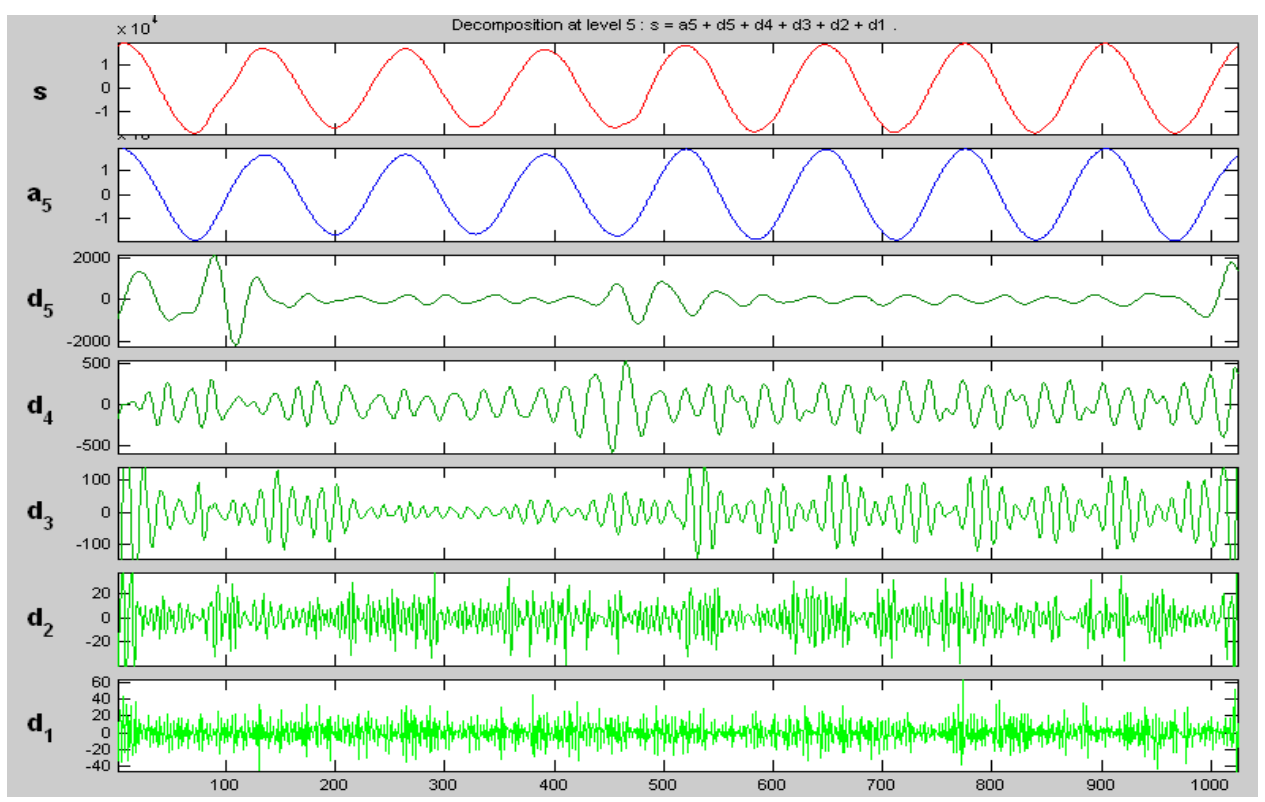

Fig. 11. Sag disturbances and five level of detail using Daubechies10

\section{Scale of colors from MIN to MAX}

Fig. 12. Colour map indicator

Table 3. Range of standard deviation for different type of signal

\begin{tabular}{ll}
\hline Type of signal & Standard deviation \\
\hline Pure signal & $1.6 \mathrm{e} 04$ \\
Voltage sag & $<1.6 \mathrm{e} 04$ \\
Voltage swell & $>1.6 \mathrm{e} 04$ \\
\hline
\end{tabular}

Table 4. Summaries of the statistical results

\begin{tabular}{lllll}
\hline Signal & $\begin{array}{l}\text { No. of } \\
\text { cases }\end{array}$ & $\begin{array}{l}\text { Std_dev } \\
<1.6 \mathrm{e} 04\end{array}$ & $\begin{array}{l}\text { Std_dev } \\
>1.6 \mathrm{e} 04\end{array}$ & Accuracy \\
\hline Sag & 77 & 7 & 70 & $90.9 \%$ \\
Swell & 34 & 34 & 0 & $100 \%$ \\
\hline
\end{tabular}

The magnitude of the voltage is $13.697 \mathrm{kV}$, which is a decrement of $37.74 \%$ of the nominal voltage. The method to obtain the voltage drop percentage is shown as following:

Voltage of system $=22 \mathrm{kV}$

Voltage of the event $=13.697 \mathrm{kV}$

Thus, drop percentage

$$
=(22 \mathrm{k}-13.697 \mathrm{k}) / 22 \mathrm{k}
$$
$=37.74 \%$

From Fig. 7, the Y-axis represents the number of cases and $\mathrm{X}$-axis is the value of standard deviation. For the above bar chart, out of 77 cases of sag events, only 18 cases are shown. The upper bar chart is plotted using the value obtained from Matlab and the lower bar chart present the value obtained from SPSS. It is observed that there is not much different between both methods and hence the value obtained from SPSS is used for further analyse since it is a computer program for statistical analysis.

From the analytical value, clearly the maximum and minimum value can be used to indicate that whether the signal is voltage sag or voltage swell. In this case, if the maximum and minimum value is exceeded the nominal voltage $(22 \mathrm{kV})$, it is a voltage swell whereby if the maximum and minimum value is below $22 \mathrm{kV}$, it is categorized as voltage sags. Therefore, these two parameters are significant in determine the type of signal at first stage.

Besides, voltage sag and swell can identify by referring the standard deviation. From Table 3, the range of the standard deviation is listed. It is important to note that the references value of the standard deviation is only valid to the signal with nominal voltage $22 \mathrm{kV}, 50 \mathrm{~Hz}$.

The above statement is being tested against a set of pure signal and a subset of 34 voltage swells as well as 77 voltage sags. The accuracy of the statement above is stated in Table 4. 


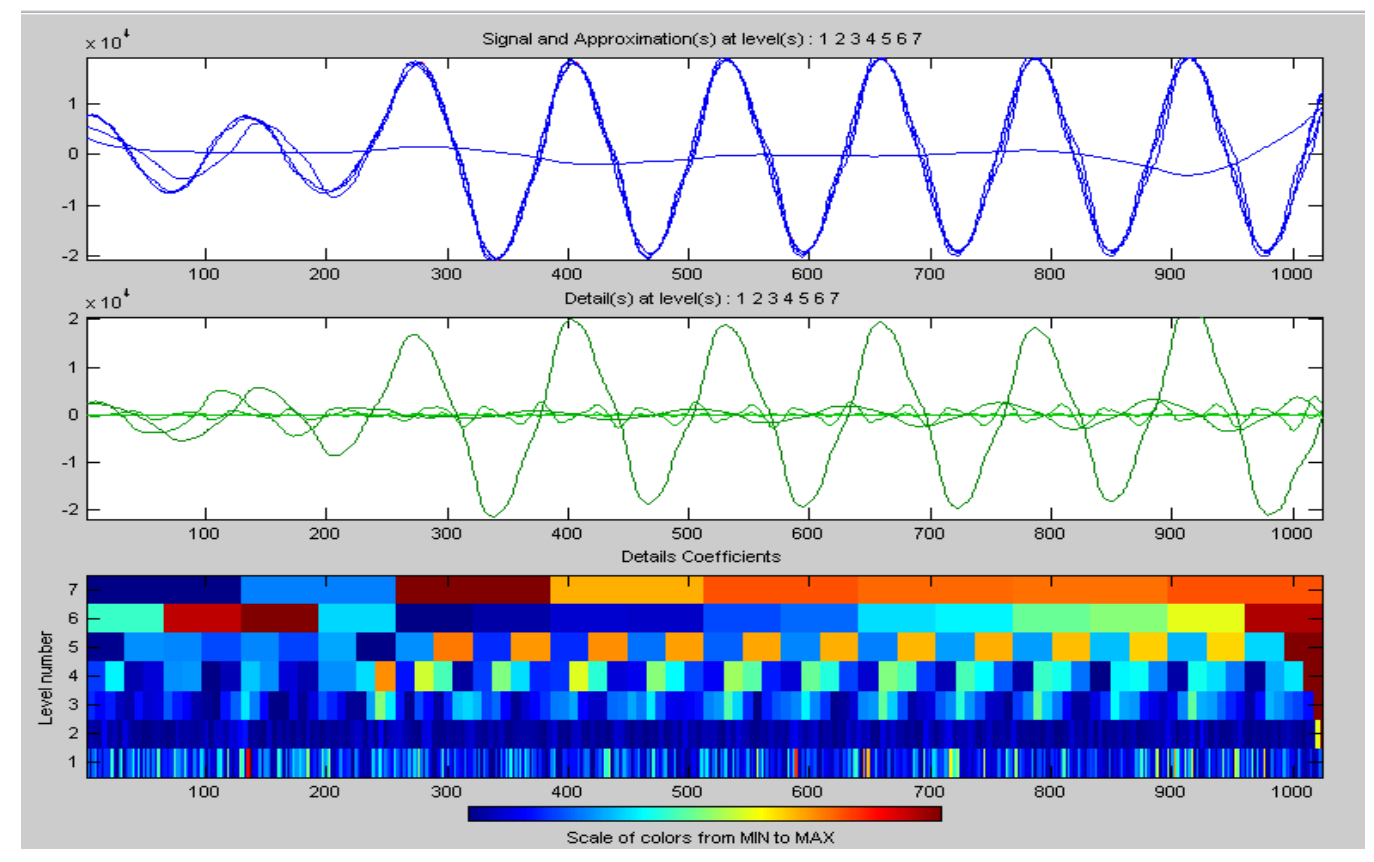

Fig. 13. Sag disturbances in superimpose mode

The statistical results prove that the standard deviation also one of the parameters in identified the type of disturbances. Notice that, for each type of disturbances, each case's standard deviation value is measured and recorded for assessment proposes between SPSS and Matlab. There is not much different between the value obtained from both SPSS and Matlab.

The height of the bars illustrates the occurrences of variables along the value of the horizontal axis. As in Fig. 8, the shape of the pure signal distribution is symmetrical.

For a disturbance's signal, the histogram shows a non-symmetrical distribution of data as shown in Fig. 9. The $\mathrm{X}$-axis indicates the magnitude of the signal is more than $22 \mathrm{kV}$. Moreover, the histogram below shows majorities of data were distributed in the range of $-2 \times 104$ to $2 \times 104$ and only minority were distributed more than magnitude $22 \mathrm{kV}$. It will indirectly provide information to the type of signal. Normally, the short-duration power quality event will happen only 0-3 period cycle. Therefore, the type of signal for the histogram below is most properly voltage swell.

In order to extract the disturbance from the signal and detect the duration of the signal, the wavelet transforms in Fig. 10 is being considered. Wavelet can be chosen with desirable frequency and time characteristics.
The basic functions in wavelet transform use time compression or dilation rather than a change in the frequency. Wavelet analysis is applied to disturbance signal obtained. The wavelet transform decomposes the disturbance signal into detailed and smooth versions. Approximate signal is smoothed versions of the original signal while detail's signal is the detailed version of the original signal which is represented as wavelet transforms coefficients at scales one (level 1). These coefficients bring the detection information.

For Fig. 10, the $\mathrm{X}$-axis represents the data size (for this case is 1024 points) and $\mathrm{Y}$-axis represents the magnitude of the power disturbances' event. The $d_{n}$ represent the details signal where $n$ equals 1 for level 1,2 for level 2 and so fore, whereas $a_{n}$ is representing the approximation signal. For above figure, it shows only $\mathrm{a}_{6}$, which means the approximate signal at level 6 . Notice that, the larger the detail levels of the signal, the smaller the frequency intervals of the analyzed signal and hence the disturbances signal can be observed clearer. Hence, smaller frequency interval is applied at a larger detail level to detect the duration of the power disturbances' event.

The first graph in Fig. 11 shows the original signal waveform. Even though the graph did not show any significant drop along the signal yet the magnitude of the signal is below the nominal voltage. Therefore, it is 
voltage sag. The $\mathrm{X}$-axis represents the data size and $\mathrm{Y}$ axis represents the magnitude of the power disturbances' event. When the voltage sag occurs all along the signal, Daub10 is introduced. In this case, Daub10 works much better than Daub4 because Daub4 does not have enough time to sense the slow changes of disturbance.

The reduction of magnitude of voltage can be observed clearly in the colour map in Fig. 12. By referring to Fig. 13, the disturbance signals are extracted from the original signal when the resolution level of voltage swells is level 7 and it can be seen clearly through the colour map indicator. The third graph in Fig. $\mathbf{1 3}$ is representing the disturbance signal (details) in the form of colour map. The $\mathrm{X}$-axis represents the number of level of resolution and the $\mathrm{Y}$-axis represent the total number of point of the signal.

Wavelet transform analysis is sensitive to signal with irregularities. For example, the power quality disturbances, but it is "blind" to a pure or constant-like behaviour of the signal. Hence, it is clear that wavelet transform analysis is an appropriate tool to detect and localize power quality disturbances. However, the scaling and wavelet functions get wider and wider as the scale increases, time localization is lost. It suggests that higher-scale decomposition is not necessary. For this project, the system will only involve up to level 6 to level 7. Therefore it does not create any unwanted trouble in wavelet the analysis.

The choice of mother wavelet plays a significant role in detecting and localizing various types of disturbances. Daubechies wavelet with $4,6,8$ and 10 filter coefficients work well in most disturbance's detection. For this project work, Daubechies wavelet with 4 filter coefficient (Daub4) is being chosen. Notice that for some disturbances such as sag or overvoltage disturbances (within 5\%), Daub4 cannot detect or localize the disturbances. However, all the selected sag and swell disturbance in this project is not within $5 \%$, therefore it does not affect the detection and localization of signals.

\section{CONCLUSION}

The result that was demonstrated proposed approach based on wavelet transform analysis is very powerful in detecting and localizing various types of power quality disturbances. From the simulated results, Daubechie4 is the best suited for detect and localize voltage sags and swells for $50 \mathrm{~Hz}$ system. Daubechie10 is suited to determine smooth disturbances. The success percentage obtained during the evaluation of the parameter of identification and classification where the entire tested disturbance's signal was more than $90 \%$.

The limitation of this research work is mainly focus on the wavelet transform method. Daubechie4 is being selected for the short and fast transient, while Daubechie10 is being selected for short and long transient analysis.

Further extension of the current study is recommended to conduct an investigation to further detection and localization capability with many other disturbances such as momentary interruptions, impulses and various types of wave shape faults. The goals are to not only detect but also to classify various types of disturbances automatically by using a certain algorithm such as artificial neutral network. A new method which is S-transform can be introduced since it overcomes the disadvantages of wavelet transform and uniquely combines a frequency dependent resolution of the timefrequency space and absolutely referenced local phase information.

\section{ACKNOWLEDGEMENT}

The researchers gratefully acknowledge the contributions of TNB members for their valuable comments, support and technical cooperation during the process of collecting the data and also the development works. The authors would like to thank the Ministry of Higher Education, Malaysia (KPT), Ministry of Energy, Green Technology and Water (KeTTHA), Research and Innovation Centre, UTHM for financially supporting this research under the Fundamental Research Grant SchemeKeTTHA (FRGS-KeTTHA) grant No. 0905 and MTUNCoE Vot.No.C025.

\section{REFERENCES}

Basu, M. and B. Basu, 2004. Application of wavelet transform for Power Quality (PQ) disturbance analysis. Proceedings of the 2nd International Conference on Power Electronics, Machines and Drives, Mar. 31-Apr. 02, IEEE Xplore Press, 269273. DOI: $10.1049 / \mathrm{cp}: 20040297$

Bingham, R.P., 1998. Sags and swells.

Dehghani, M.J., 2009. Comparison of S-transform and wavelet transform in power quality analysis. World Acad. Sci. Eng. Technol., 26: 395-398.

Dugan, R.C., M.F. McGranaghan, S. Santoso and H.W. Beaty, 2012. Electrical Power Systems Quality. 3rd Edn., McGraw-Hill, ISBN-10: 0071761551, pp: 580 . 
Gaouda, A.M., M.M.A. Salama, M.R. Sultan and A.Y. Chikhani, 1999. Power quality detection and classification using wavelet-multiresolution signal decomposition. IEEE Trans. Power Deliv., 14: 1469-1476. DOI: 10.1109/61.796242

Heydt, G.T. and A.W. Galli, 1997. Transient power quality problems analyzed using wavelets. IEEE Trans. Power Deliv., 12: 908-915. DOI: $10.1109 / 61.584412$

Kanitpanyacharoean, W. and S. Premrudeepreechacharn, 2004. Power quality problem classification using wavelet transformation and artificial neural networks. Proceedings of the Power Systems Conference and Exposition, Oct. 10-13, IEEE Xplore Press, pp: 1496-1501. DOI: 10.1109/PSCE.2004.1397630

Kasula, V.D.K., 2007. Classification of power quality disturbance signals using FFT, STFT, wavelet transforms and neural networks-A comparative analysis. Proceedings of the International Conference on Computational Intelligence and Multimedia Applications, Dec. 13-15, IEEE Xplore Press, Sivakasi, Tamil Nadu, pp: 335-340. DOI: 10.1109/ICCIMA.2007.279

Kim, C.H., S.W. Park, R.K. Aggarwal and A.T. Johns, 1999. A noise suppression method for improvement of power quality using wavelet transforms. Proceedings of the IEEE Power Engineering Society Summer Meeting, Jul. 18-22, IEEE Xplore Press, Edmonton, Alta., pp: 414-419. DOI: 10.1109/PESS.1999.784384

Kopparapu, C. and A. Chandrasekaran, 1998. A study on the application of wavelet analysis to power quality. Proceedings of the 30th Southeastern Symposium on System Theory, Mar. 8-10, IEEE Xplore Press, Morgantown, WV., pp: 350-353. DOI: 10.1109/SSST.1998.660091
Milind, A.G., K.S. Kumar, B.R.S. Kumar and M.L. Sudheer, 2008. Detection and estimation of voltage disturbances using wavelet transforms. Proceedings of the 10th International Conference on Bangalore Electromagnetic Interference and Compatibility, Nov. 26-27, IEEE Xplore Press, Bangalore, pp: 8186.

Poisson, O., P. Rioual and M. Meunier, 1999. New signal processing tools applied to power quality analysis. IEEE Trans. Power Deliv., 14: 561-566. DOI: 10.1109/61.754104

Poisson, O., P. Rioual and M. Meunier, 2000. Detection and measurement of power quality disturbances using wavelet transform. IEEE Trans. Power Deliv., 15: 1039-1044. DOI: 10.1109/61.871372

Resende, J.W., M.L.R. Chaves and C. Penna, 2001. Identification of power quality disturbances using the MATLAB wavelet transform toolbox. Proceedings of the International Conference on Power Systems Transients, (PST' 01), Rio de Janeiro, Brasil.

Santoso, S., E.J. Powers and W.M. Grady, 1994. Electric power quality disturbance detection using wavelet transform analysis. Proceedings of the IEEE-SP International Symposium on Time-Frequency and Time-Scale Analysis, Oct. 25-28, IEEE Xplore Press, Philadelphia, PA., pp: 166-169. DOI: 10.1109/TFSA.1994.467267

Santoso, S., E.J. Powers, W.M. Grady and P. Hofmann, 1996. Power quality assessment via wavelet transform analysis. IEEE Trans. Power Deliv., 11: 924-930. DOI: 10.1109/61.489353

Talaat, N., W.R. Ibrahim and G.L. Kusic, 2008. New technique for categorization of power quality disturbances. Proceedings of the Power Quality and Supply Reliability Conference, Aug. 27-29, IEEE Xplore Press, pp: 11-16. DOI: 10.1109/PQ.2008.4653730 